\title{
Skull fractures in children: a population study
}

\author{
A J Johnstone, S H Zuberi, W G Scobie
}

\begin{abstract}
Objective-To provide information about children with a skull fracture in the Edinburgh area, since head injury is the single most important traumatic cause of death in children over 1 year of age.

Methods-During the period January 1983 to December 1989, all children in the Edinburgh area under 13 years of age who sustained a skull fracture were identified. Details of the children who died primarily from a head injury, and the total number of children who were admitted to hospital with a head injury not associated with a skull fracture, were also documented. Data were obtained from the General Register Office for Scotland, Edinburgh Fiscal Office records, and Lothian Health Board records. Data on cause of injury and clinical condition were obtained.
\end{abstract}

Results-3498 children under 13 years of age were admitted to hospital after sustaining a head injury and 27 died primarily as a result of their injuries; 409 children had a skull fracture and 76 of this group had cranial CT scans. Nineteen of the CT scans performed were on children who had been admitted to hospital in a coma, and all had abnormal scan findings. In addition all children with intracerebral haematomas/haemorrhages had been admitted in a coma. Road traffic accidents accounted for the greatest number of deaths (84\%), associated injuries, and overall morbidity.

Conclusions-To reduce the incidence of head injuries, and the associated morbidity and mortality, the following are required: identify at risk groups; promote accident prevention; publicise the findings and guidelines concerning childhood head injuries; ensure that all children with head injuries have appropriate investigations and begin treatment as early as possible; establish clinical audit; and set up regional rehabilitation teams.

(F Accid Emerg Med 1996;13:386-389)

Key terms: head injury; children; skull fracture

Head injury is the single most important traumatic cause of death in children over 1 year of age. ${ }^{1}$ Despite its importance, there are few epidemiological data available in the United Kingdom about head injured children, ${ }^{2}$ and health service statisticians have had to rely heavily upon North American data ${ }^{3}$ which have been shown to be of limited use. ${ }^{45}$ Our study provides information about all children under
13 years of age in the Edinburgh area who sustained a skull fracture, during the seven year period 1983 to 1989 . Edinburgh provides all paediatric services for the city and the immediate local communities (a population of approximately 92000 under 13 years of age in 1986).

\section{Methods}

During the period January 1983 to December 1989 , we identified all children in the Edinburgh area, under 13 years of age, who had sustained a skull fracture. In addition, the details of the children who died primarily from a head injury, and the total number of children who were admitted to hospital with a head injury not associated with a skull fracture, were also documented. All children were admitted to hospital in keeping with the criteria accepted by the Department of Health and Social Security. ${ }^{6}$ Data were obtained from the General Register Office for Scotland, Edinburgh Fiscal Office records, and Lothian Health Board records. The following patient details were recorded for those children with a skull fracture: age, sex, source of referral, admission hospital, mechanism of injury, admission level of consciousness (using appropriate coma scales), computerised tomographic (CT) scan results (where performed), significant associated injuries, early outcome at the time of discharge or transfer (assessed using the Glasgow outcome scale), ${ }^{7}$ and initial disposal of the patient following treatment at the admission hospital. Children were classified as having a major head injury if a CT scan of the head identified an intracranial injury requiring active treatment (surgery and/or intensive care), or if the patient was admitted in coma.

\section{Results}

TOTAL NUMBERS

In the seven year study period, 3498 children in the Edinburgh area under 13 years of age were admitted to hospital after having sustained a head injury.

Twenty seven children died primarily as a result of their head injuries (23 had sustained a skull fracture). Fifteen children died following admission to hospital, and 12 died at the scene of the accident or were pronounced dead on arrival at hospital. On average four children per 100000 population under 13 years of age died primarily from their head injuries during each of the study years in the Edinburgh area.

Of the 3498 children admitted with a head injury, we paid particular attention to the 409 children who had sustained a skull fracture (64 per 100000 population per year) and all other 
Table 1 Paediatric admissions

\begin{tabular}{llllll}
\hline & \multicolumn{2}{c}{ Paediatric surgical units } & & \multicolumn{2}{c}{ Neurosurgical units } \\
\cline { 2 - 3 } \cline { 5 - 6 } & Minor HI & Severe HI & & Minor HI & Severe HI \\
\hline 1983 & 32 & 1 & 12 & 3 \\
1984 & 38 & 0 & 13 & 9 \\
1985 & 39 & 2 & 10 & 5 \\
1986 & 49 & 1 & & 9 & 6 \\
1987 & 58 & 2 & 10 & 2 \\
1988 & 47 & 1 & 11 & 5 \\
1989 & 34 & 1 & 5 & 4 \\
$1983-89$ & 297 & 8 & 70 & 34 \\
\hline
\end{tabular}

HI, head injury.

figures relate to this group of children. Similar numbers of children sustained skull fractures throughout each year of the study (table 1); $367(90 \%)$ had a minor head injury, and 42 $(10 \%)$ had a major head injury (table 1 ).

SEX AND AGE

Skull fractures were twice as common in boys as girls. We looked at children under 5 years of age (preschool age), and between the ages of 5 and 13 years (school age) (table 2). Boys sustained $60 \%$ of the skull fractures in the under 5 group and $74 \%$ of the skull fractures in the over 5 group. Of the children with major head injuries, $62 \%$ of the under 5 group and $72 \%$ of the over 5 group were boys.

SOURCE OF PATIENT REFERRAL

Ninety eight per cent of the children with a skull fracture were brought directly to one of Edinburgh's accident and emergency departments. General practitioners referred only $2 \%$ of the patients.

\section{ADMISSION HOSPITAL}

The surgical paediatric units received $75 \%$ of the children (305) of whom eight (3\%) had a major head injury and were transferred to the neurosurgical units; 104 children (25\%) were admitted directly to Edinburgh's neurosurgical units and $34(33 \%)$ of them had a major head injury (table 1 ).

MECHANISM OF INJURY

Throughout the study period, there was little annual variation with respect to the relative frequencies of the mechanisms of injury (table 3). Falls outside accounted for $43.5 \%$ of the admissions; falls inside, $23 \%$; road traffic accidents, $21 \%$; being struck by a missile, $6.5 \%$; and non-accidental injuries, 3\%. The mechanism of injury was not documented in $3 \%$ of the cases.

The proportion of injured boys to girls was similar within each mechanism of injury category. However, there was a strong association between age and the various mechanisms

Table 2 Age and sex of children

\begin{tabular}{llcllc}
\hline \multirow{2}{*}{ Age } & \multicolumn{2}{l}{ Skull fracture with } & minor $H I$ & & \multicolumn{2}{l}{ Skull fracture with severe $H I$} \\
\cline { 2 - 3 } & Boys & Girls & & Boys & Girls \\
\hline Under 5 & 125 & 85 & 8 & 5 \\
5 to 13 & 116 & 41 & & 21 & 8 \\
Total & 241 & 126 & 29 & 13 \\
\hline
\end{tabular}

HI, head injury of injury. All children admitted following nonaccidental head injuries were under 5 years of age. Also, $89 \%$ of the children who had fallen inside, and $51 \%$ of children who had fallen outside, were under 5 years of age. In comparison, $68 \%$ of the children who had been struck by a missile, and $71 \%$ of the children who had been injured in a road traffic accident, were over 5 years of age.

ADMISSION LEVEL OF CONSCIOUSNESS AND CT SCAN RESULTS

Seventy six children had cranial CT scans. Thirty eight of the scans were reported as being normal. Of the others, 16 children had extradural haematomas, nine had subdural haematomas, nine had intracerebral haematomas/haemorrhages, nine had subarachnoid haemorrhages, and the remainder (33 cases) had cerebral contusions in isolation or in combination with diffuse cerebral swelling. Nineteen of the children scanned had been in coma at the time of admission and all of them had abnormal scan findings. In addition all of the children with intracerebral haematomas/haemorrhages had been admitted in coma. Of the children with abnormal scan findings, $29 \%$ required drainage of intracranial haematomas, and $45 \%$ underwent intracranial pressure monitoring.

\section{ASSOCIATED INJURIES}

The incidence of significant associated injuries differed depending upon the mechanism of injury: falls inside, $2 \%$; being struck by a missile, $6 \%$; falls outside, $11 \%$; non-accidental injury, $31 \%$; and road traffic accidents, $38 \%$.

Significant associated injuries were present in $9 \%$ of the children with a minor head injury, and in $39 \%$ of those with a major head injury (table 4). Sixty two per cent of the associated injuries were orthopaedic. Multiple associated injuries involving more than one body system occurred in $1 \%$ of the children with minor head injuries, and in $9 \%$ of those with major head injuries.

\section{PATIENT OUTCOME}

Early patient outcome, assessed using the Glasgow outcome scale (GOS), differed according to the mechanism of head injury. Ninety seven per cent of children injured by a fall inside, $96 \%$ of those injured by a missile, $94 \%$ of those injured by a fall outside, and $91 \%$ of those injured non-accidentally had a good early outcome (GOS of 5). Children injured in road traffic accidents did least well after injury, with only $52 \%$ making a good early recovery. Eighty four per cent of the children who died were injured in road traffic accidents.

PATIENT DISPOSAL

During the seven year study period, 357 (87\%) of the children with a skull fracture were fit to be discharged directly into the community. The neurosurgical units transferred 38 (36.5\%) of their children to the surgical paediatric units within the city. Twelve children were transferred from the neurosurgical and surgical 
Table 3 Mechanisms of injury

\begin{tabular}{lcccccc}
\hline & Fall inside & Fall outside & RTA & Missile & NAI & Not known \\
\hline 1983 & 13 & 21 & 11 & 1 & 1 & 1 \\
1984 & 8 & 33 & 13 & 2 & 3 & 1 \\
1985 & 12 & 26 & 11 & 5 & 0 & 2 \\
1986 & 14 & 31 & 11 & 6 & 1 & 2 \\
1987 & 18 & 25 & 22 & 5 & 2 & 0 \\
1988 & 19 & 22 & 10 & 4 & 4 & 5 \\
1989 & 11 & 20 & 9 & 3 & 0 & 1 \\
$1983-89$ & 95 & 178 & 87 & 26 & 11 & 12 \\
\hline
\end{tabular}

Table 4 Associated injuries

\begin{tabular}{lll}
\hline & Skull fracture with minor $H I$ & Skull fracture with severe $H I$ \\
\hline Face & 6 & 3 \\
Spine & 2 & 0 \\
Thorax & 3 & 5 \\
Abdomen/pelvis & 1 & 2 \\
Limbs & 25 & 11 \\
Total & $37(9 \%)$ & $21(39 \%)$ \\
\hline
\end{tabular}

HI, head injury

paediatric units to other hospitals within Edinburgh for convalescence and rehabilitation.

\section{Discussion}

In the Edinburgh area, 4.2 children per 100000 population under 13 years of age died as a direct consequence of their head injuries. This figure is considerably lower than the mortality rates quoted from North America, ${ }^{3}$ but similar to North East England (5.3 children per 100000$).^{1}$ The proportion of children who died before admission was also similar for the two United Kingdom centres: $44 \%$ in the Edinburgh area compared with $49 \%$ in the North East of England.

Road traffic accidents are the commonest source of severe and fatal head injuries. ${ }^{5}$ In addition, a larger proportion of children involved in road traffic accidents had a poor early outcome when compared with other head injured children; however, children injured in road traffic accidents frequently have significant associated injuries which contribute to the higher levels of morbidity and mortality. ${ }^{1}$ Our study suggests that the results of road safety education have been disappointing to date and need to be reviewed.

Ten per cent of the children with a skull fracture had a major head injury. We agree with the findings of Teasdale and colleagues that the presence of a skull fracture greatly increases the risk of a child having a significant intracranial injury, especially if the child also has a persistently abnormal conscious level. ${ }^{4}$

During recent years, opinions have differed concerning the place of routine skull $x$ rays in head injured children, and some groups ${ }^{89}$ feel that the need for $x$ rays should be based upon the patient's clinical condition. However, other studies suggest that clinical findings alone do not accurately identify the children at risk of significant sequelae, even in those children considered to have minor head injuries. ${ }^{10-12}$ In addition the results of several studies reflect the importance of detecting and treating intracranial haematomas at an early stage. ${ }^{13}$ In our centre we use skull $x$ rays to exclude a fracture in those children who have a normal level of consciousness: these children would not require further investigations, and need not be admitted. ${ }^{4}$ Children with persistently subnormal conscious levels, abnormal neurological signs, or who have had a seizure should have a CT scan performed as a primary investigation, ${ }^{414}$ which would therefore obviate the need for skull $x$ rays. As the availability of CT scanning becomes more widespread, it would be ideal for children with a skull fracture and a normal conscious level to have a CT scan, in the hope that this would further reduce morbidity. ${ }^{410} 14$

Twelve patients (3\%) required a period of convalescence and rehabilitation after their head injury. This figure represents only the more seriously injured children and underestimates the total number of children with less obvious residual problems such as learning difficulties or changes in personality, which are easily missed..$^{15}$ If head injured children were referred routinely to a multidisciplinary rehabilitation team headed by a paediatrician, it might be possible to detect and assess the residual effects of head injury at an earlier stage, and provide the necessary support. Hopefully this approach would be of long term benefit to the children involved.

In order to reduce the incidence of head injuries-and the associated morbidity and mortality-we require to: identify at risk groups; promote accident prevention; widely publicise the findings and guidelines concerning childhood head injuries ${ }^{614}{ }_{16}$; ensure that all children with head injuries have appropriate investigations and start treatment as early as possible; establish clinical audit; and set up regional rehabilitation teams.

We thank Professor J D Miller of the Department of Clinical Neurosciences, Western General Hospital, Edinburgh, for his advice. We also thank Dr J W Nicol and Dr T J Draper of the Department of Paediatric Surgery, The Royal Hospital for Sick Children, Edinburgh; Miss J L Tocher of the Department of Clinical Neurosciences, Western General Hospital, Edinburgh the staff of the Records Department, The Royal Hospital fo Sick Children, Edinburgh; and the staff at the General Register Office for Scotland, for their help in the data collection.

1 Sharples PM, Storey A, Aynsley-Green A, Eyre JA Avoidable factors contributing to death of children with head injury. BMF 1990;300:87-91.

2 Sharples PM, Eyre JA. Children with head injuries. BMf 1990;i:1289-90.

3 Annegers F. The epidemiology of head trauma in children In: Shapiro I, ed. Pediatric head trauma. New York: Futura Publishing, 1983:1-10.

4 Teasdale GM, Murray G, Anderson E, Mendelow AD, MacMillan $\mathrm{R}$, Jennett $\mathrm{B}$, et al. Risks of acute traumatic intracranial haematoma in children and adults: implications for managing head injuries. BMF 1990;300:363-7.

5 Sharples PM, Storey A, Aynsley-Green A, Eyre JA. Cause of fatal childhood accidents involving head injury in Northern region, 1979-86. BMF 1990;301:1193-7.

6 Lewis AF, ed. The management of acute head injury. In: Harrogate Seminar Report No 8. London: Department of Health and Social Security, 1983:1-85.

7 Jennett B, Bond M. Assessment of outcome after severe brain damage. Lancet 1975;iii: $480-4$.

8 Thornbury JR, Campbell JA, Masters SJ, Fryback DG. Skull fracture and the low risk of intracranial sequelae in minor head trauma. Am $\mathcal{f}$ Roentgenol 1984;143:661-4.

9 Boulis ZF, Dick R, Barnes NR. Head injuries in children Boulis ZF, Dick R, Barnes NR. Head injuries in children aetiology, symptoms, physical

10 Servadei F, Ciucci G, Morichetti A, Pagano F, Burzi M, Servadei F, Ciucci G, Morichetti A, Pagano F, Burzi M,

1 Rivara F, Tanaguchi D, Parish RA, Stimac GK, Mueller B. Rivara F, Tanaguchi D, Parish RA, Stimac GK, Mueller B.
Poor prediction of positive computed tomographic scans 
by clinical criteria in symptomatic pediatric head trauma. Pediatrics 1987;80:579-84.

Miller JD, Jones PA, Dearden NM, Tocher JL. Progress in

the management of head injury. Brf Surg 1992;79:60-4

13 Miller JD, Tocher JL, Jones PA. Extradural haematoma -

earlier detection, better results. Brain Injury 1988;2:

83-6.
14 Editorial. Head to head over Harrogate. Lancet 1991;335: 695-6.

5 Greenspan AI, MacKenzie EJ. Functional outcome after pediatric head injury. Pediatrics 1994;94:425-32.

16 Group of Neurosurgeons. Guidelines for initial management after head injury in adults. $B M \mathcal{F}$ 1984;288:983-5.

\section{ADVANCE NOTICE \\ MID-TRENT PAEDIATRIC TRAUMA CONFERENCE}

\section{JUNE $2^{\text {nd }}$ and $3^{\text {rd }}, 1997$ \\ Venue: NOTTINGHAM}

This two day conference, addressing the challenges, controversies and future of paediatric trauma management, will feature local, national and international speakers.

MAKE A NOTE IN YOUR DIARY! BOOKING DETAIIS AVAILABLE EARLY 1997 